\title{
Forging Ahead, Despite Uncertainties
}

I have annually written the opening editorial for the Journal of the Brazilian Chemical Society (JBCS), and every year the message is like "Enjoy reading our journal and let's work for a wonderful coming year".

In the past two years, we have gone through difficult times and big changes in our lives. Since the end of 2019, the world has been trying to understand how to live with the COVID-19 pandemic. If in one moment the discovery of vaccines seemed to be the solution for prevention of this coronavirus disease, other factors like anti-vaccination movements and science denialism have changed our expectations. It is astonishing how fast the world scientific community reacted to this threat making vaccines available for almost everyone. However, at same the speed, science denial movements have destroyed the chance of a quick return to more normal days. Many countries have faced three or even more waves of high infection rates, leading to an unpredictable time to overcome this problem.

Brazil, a country with a tradition of vaccination, has been facing a wave of denialism that has caused devastating problems for the population, leading to a high number of deaths due to COVID-19. The behavior of one important leader of our nation, the president, who announced he would not get vaccinated, has generated a wave of disrespect for the sanitary measures to prevent the disease. In addition, budget constraints generated by difficulties in the economy have raised an extra barrier for the investment in science and technology. Putting together these two points, we expect challenging times in the coming year and in others ahead. The insufficient funding of research has already reflected on science productivity, and solutions for many problems faced by our country in the environment, energy and food supply areas will certainly take a longer time.

In this scenario of difficult times, in 2021 we had to raise the APCs (article processing charges) for the JBCS. It seems this decision together with the problems from the pandemic that have impacted science activities throughout the world have led to a decrease in the number of papers submitted for publication in the JBCS. We hope this situation will reverse for the better in the near future and our rhythm of submissions gets back to the normal track.

Yet there is good news to celebrate. The JBCS has experienced a high evolution in its impact factor in 2021. The JBCS IF released by Clarivate Analytics showed an increase of $31 \%$ in comparison with that of 2020 , which is celebrated by the editors, authors, and the Brazilian Chemical Society (SBQ), our sponsor. This mark results from a joint effort of persistence of our authors, editors, sponsor, and editorial office in making the journal a quality scientific communication organ with respectful visibility in its community.

This year, as part of the "Post 2022 Chemistry Movement - Sustainability and Sovereignty", launched by the SBQ inspired by the UNESCO initiative to celebrate 2022 as "The International Year of Basic Sciences for Sustainable Development", the theme "Chemistry for Sustainable Development". Contributors from Brazil and abroad were invited to submit papers, and this thematic issue will be launched by the time of the 2022 SBQ annual meeting to be held in Maceió, from May $31^{\text {st }}$ to June $3^{\text {rd }}$. After two years of pandemic crisis and virtual SBQ meetings, all the expectations are that we will have an in-person meeting. At the same time, the SBQ will be discussing a new and broad program for chemistry in the next decades, focusing on sustainability and sovereignty.

As I do every year, now I should announce a change in the editorial procedures. Beginning with the issue 33-1, we have decided to publish the names of the editors (in chief and associated) who were responsible for the editorial process of each article - here we should emphasize that the names of all reviewers are published every year in the issue 12 . With this procedure, we believe the JBCS becomes more transparent in its editorial process and conforms to a demand related to strategies of Open Science Policy.

Finally, I acknowledge the collaboration of authors and reviewers for their support to keep the high standards of the journal. The JBCS and SBQ are very grateful for their work as well as for that of the editors and advisory board who devote part of their time to our journal.

Enjoy reading our journal and let's work for a wonderful 2022.

Paulo Cezar Vieira ${ }^{\circledR}$ Editor-in-chief of the Journal of the Brazilian Chemical Society Universidade de São Paulo (USP), Ribeirão Preto-SP, Brazil

\section{Reference}

1. The International Year of Basic Sciences for Sustainable Development; https://www.iybssd2022.org/en/home/, accessed in December 2021. 